Gut, 1963, 4, 95

\title{
The aetiology and management of ascites in patients with hepatic cirrhosis: A review
}

\author{
SHEILA SHERLOCK AND STANLEY SHALDON \\ From the Department of Medicine, Royal Free Hospital, London
}

Ascites, if associated with parenchymatous liver disease, implies hepato-cellular failure and portal venous hypertension. The commonest cause is Laennec's cirrhosis. Less often it complicates terminal biliary cirrhosis, haemochromatosis, hepatolenticular degeneration, or acute virus hepatitis.

\section{AETIOLOGY}

Starling (1896) suggested that the interchange of fluid between the blood and the tissue spaces is controlled by the balance between the capillary blood pressure, forcing fluid into the tissue spaces, and the osmotic pressure of the plasma proteins, retaining fluid in the vascular compartment (Fig. 1). The equilibrium may be stated as:-

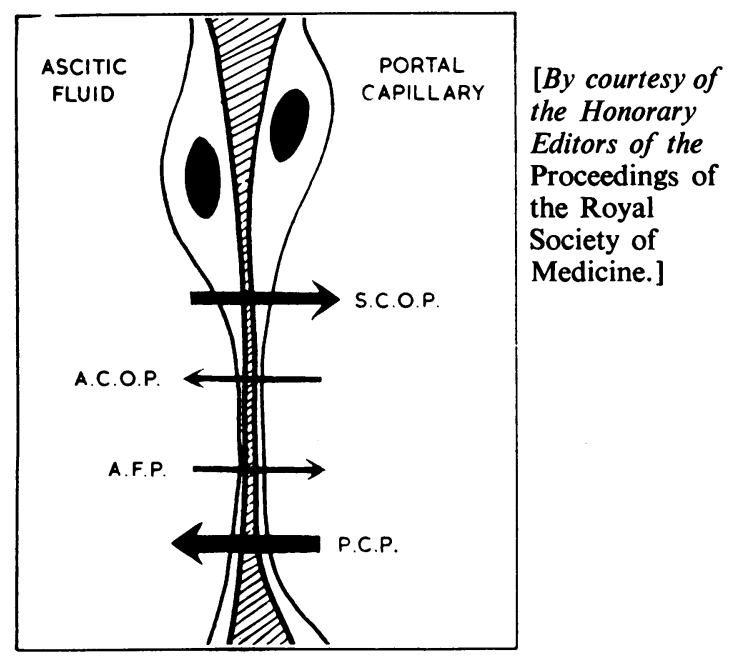

FIG. 1. The ascitic fluid is separated from the capillary lumen by the peritoneal membrane and the portal capillary wall. The forces keeping fluid in the capillaries are the colloid osmotic pressure of the serum (S.C.O.P.) and the hydrostatic pressure of the ascitic fluid (A.F.P.). The forces tending to form ascites are the portal capillary pressure (P.C.P.) and the colloid osmotic pressure of the ascitic fluid (A.C.O.P.). In a steady state these forces should balance.
Plasma colloid osmotic pressure - Ascitic colloid osmotic pressure

$=$ Portal capillary pressure - intra-abdominal hydrostatic pressure

It is clear therefore that there are probably at least two important factors in the formation of ascites, namely, the plasma colloid osmotic pressure and the portal venous pressure.

PLASMA COLLOID OSMOTIC PRESSURE The plasma colloid osmotic pressure is largely governed by the plasma albumin level. In cirrhotic patients albumin turnover rates are decreased reflecting impaired synthesis (Wilkinson and Mendenhall, 1963). Plasma albumin levels are low and hence colloid osmotic pressure is reduced. It has been suggested that oedema is formed when the plasma albumin level falls below $3 \cdot 1$ g. per $100 \mathrm{ml}$. or $270 \mathrm{~cm}$. water colloid osmotic pressure (Post and Patek, 1942; Bjørneboe, Brun, and Raaschou, 1949). This relationship is, however, by no means constant, and considerable overlap in the range of serum albumin or colloid osmotic pressure levels may be found in patients with liver disease with and without ascites (Higgins, Kelsall, O'Brien, Stewart, and Witts, 1947); Giges and Kunkel, 1954). Moreover, if a normal serum colloid osmotic pressure is maintained by intravenous albumin infusions oedema does not always resolve (Faloon, Eckhardt, Murphy, Cooper, and Davidson, 1949; Losowski and Atkinson, 1961). It is important, furthermore, to stress that the measurement of the serum albumin in a patient with established fluid retention does not necessarily reflect the level of serum albumin at the time of the development of fluid retention. The possibility of ascites developing in the presence of a normal serum albumin level with the subsequent dilution of the albumin in a larger pool is suggested by the presence of a normal total body albumin level in patients with cirrhosis with ascites and low serum albumin concentrations (Wilkinson and Mendenhall, 1963).

However, when all four components of the Starling formula are measured the effective colloid osmotic 
pressure still provides a better dividing line between those patients with and without ascites than does the effective portal pressure (Cherrick, Kerr, Read, and Sherlock, 1960).

PORTAL VENOUS PRESSURE When considered as an isolated phenomenon, portal pressure cannot be quantitatively related to the presence of ascites. For instance, portal hypertension due to cirrhosis may exist in the absence as well as in the presence of ascites. Experimental obstruction to the portal vein is rarely sufficient to produce ascites unless at the same time the animal is rendered hypoproteinaemic by plasmapheresis (Bolton, 1914; Berman and Hull, 1952). Similarly, if a patient with extrahepatic portal hypertension suffers a gastrointestinal haemorrhage, or if for any other reason the plasma protein level falls, then ascites may develop. The disappearance of ascites is associated with an increase in the concentration of the plasma proteins, even though portal hypertension remains. Portal hypertension serves to localize fluid retention in the peritoneal cavity rather than in the peripheral tissues.

PLASMA-ASCITES INTERCHANGE Fluid exchange between the ascitic and vascular compartments is mainly through the visceral peritoneum; the role of the lymphatics will be considered later. Once formed, ascitic fluid can exchange with blood through an enormous capillary bed under the visceral peritoneum. The net transfer pressure is the sum of known hydrostatic forces controlling fluid transfer across the membrane, assuming that it is a simple semipermeable one. The net transfer is usually positive in those forming ascites and usually, but not constantly, negative in those without ascites (Cherrick et al., 1960). The association of a positive transfer pressure favouring the formation of ascites at a time when it is absent might indicate that the capillary peritoneal membrane is actively preventing transfer of fluid and is playing a dynamic vital role. Again a strongly positive transfer pressure in patients with ascites who are not rapidly accumulating fluid, but indeed may be losing it, might indicate that the fluid is maintained in the portal capillaries against a head of pressure by the activity of this living capillary peritoneal membrane. Alternatively, the fluid might be continually removed by the lymphatics. A further and hitherto uninvestigated factor is the rate of blood flow along the capillary membrane where fluid exchange occurs, as undoubtedly the rate of formation and reabsorption of ascitic fluid will be determined to some extent by the volume velocity of the fluid bathing the capillary surface. The mechanism by which patients with ascites maintain a steady state when formation equals reabsorption is not known.
Ascites is continually circulating and has a half turnover time of about one hour (Schoenberger, Kroll, Sakamoto, and Kark, 1952). The constituents of the fluid are in a dynamic equilibrium with those of the plasma.

THE ROLE OF LYMPH FLOW Ascites can be produced in a dog by constriction of the inferior vena cava above the entry of the hepatic vein, so causing hepatic congestion (Bolton, 1914). This is associated with an increased production of hepatic lymph which then extravasates through the capsule into the peritoneal cavity (Volwiler, Grindlay, and Bollman, 1950; Hyatt and Smith, 1954). In hepatic cirrhosis the obstruction to portal blood flow is post-sinusoidal (Shaldon, Dolle, Guevara, Iber, and Sherlock, 1961), presumably secondary to scarring and pressure of regenerating nodules on the hepatic veins. This outflow 'block' is believed to cause an increased production of hepatic lymph (McDermott, 1958; Welch, Welch, and Carter, 1959). In experimental cirrhosis hepatic lymph flow is certainly increased (Cain, Grindley, Bollman, Flock, and Mann, 1947). In cirrhotic patients the thoracic duct is dilated and flow through it is increased three- to six-fold; ascites has been relieved by cannulating the thoracic duct and draining lymph (Dumont and Mulholland, 1960). The numbers of subcapsular and hilar lymphatics are increased in patients with ascites (Baggenstoss and Cain, 1957; Leger and Guyet, 1957). Ascites disappears if hepatic outflow 'block' is relieved by side-to-side portacaval anastomosis (McDermott, 1958; Welch et al., 1959). Ascites might therefore be produced from hepatic lymph and carried away in the hepatic lymph channels to the thoracic duct. This could account, in part, for difficulties in interpreting the mechanism of ascites formation simply by the Starling equilibrium. The reabsorption into the lymphatics, in contrast to the diffusion into the capillaries, is not selective: all protein fractions are carried away equally (Dykes, 1961).

This theory does not explain the development of ascites in patients with extrahepatic portal obstruction who become hypoproteinaemic, the relief of ascites obtained by end-to-side portacaval anastomosis (with no obvious relief of the hepatic outflow 'block'), or the close relationship found between serum colloid osmotic pressure and the presence of ascites.

\section{ELECTROLYTE CHANGES}

SODIUM RETENTION Whereas cirrhotic patients without ascites have a normal urinary sodium excretion, those developing ascites retain sodium avidly 
(Eisenmenger, 1952) and often less than $1 \mathrm{mEq}$. is excreted daily in the urine. Such low sodium excretion is not confined to the urine, being also found in sweat, saliva, and even colonic secretions (Bongiovanni and Eisenmenger, 1951). Serum sodium levels are also lower than normal, usually about $130 \mathrm{mEq}$. per litre (Eisenmenger, 1952). This does not reflect sodium deficiency, as the greatly expanded extracellular sodium space results in an actual increase in total body stores of sodium (Birkenfeld, Leibman, O'Meara, and Edelman, 1958).

Sodium retention results from tubular reabsorption of sodium to an almost quantitative degree. Most sodium is reabsorbed in the proximal tubule and the mechanism for this excessive reabsorption in patients with fluid retention is unknown, although recently a humoral factor has been postulated (de Wardener, Mills, Clapham, and Hayter, 1961; Mills, de Wardener, Hayter, and Clapham, 1961). Distal tubular reabsorption of sodium is partly controlled by aldosterone and increased secretion rates of aldosterone from the adrenals has been shown in cirrhotic patients with ascites (Ulick, 1959). Undoubtedly, aldosterone alone cannot be responsible for sodium retention to the degree seen in cases of cirrhosis with ascites, as completely suppressing the production of aldosterone by an $11 \beta$ hydroxylase inhibitor (Metopirone) fails to produce a sodium diuresis when it is given alone (Shaldon and McLaren, 1960), nor is the administration of a peripheral aldosterone antagonist alone (spironolactone) usually effective in producing a sodium diuresis in patients with ascites (Shaldon, McLaren, and Sherlock, 1960).

WATER RETENTION Patients with cirrhosis have an impaired water excretion (Birchard, Prout, Williams, and Rosenbaum, 1956). This might be due to the activity of antidiuretic hormone, increased amounts of which can be found in jugular venous blood of some patients with cirrhosis forming ascites (Lee and Bisset, 1958). Both the pitressin tolerance test and the nicotine test, which depends on endogenous production of antidiuretic hormone are, however, normal in cirrhosis (Bernstein, Weston, Ross, Grossman, Hanenson, and Leiter, 1953). We have recently observed the formation of ascites in a patient with cirrhosis and coexistent nephrogenic diabetes insipidus secondary to potassium depletion. In this patient the administration of antidiuretic hormone had no effect on free water clearance or urinary osmolality.

Most probably the defect in water excretion results from proximal tubular reabsorption of sodium being so great that reducted amounts pass to the distal tubule and so 'free water' cannot be generated in adequate amounts (Schedl and Bartter, 1960). It can be remedied by giving an osmotic diuretic such as Mannitol which flushes sodium distally and so allows free water to be generated (Shaldon et al., 1960).

POTASSIUM CHANGES The serum potassium level is normal or slightly depressed but the body's exchangeable potassium is decreased (Birkenfeld et al., 1958). This is not only due to excessive loss of the ion but to the cells failing to maintain their potassium content (cellular depletion) (De Deuxchaisnes, Collet, Busset, and Mach, 1961). Reduction in total muscle mass is also a contributory factor.

\section{RENAL FUNCTION}

The relationship of sodium excretion to renal blood flow and the glomerular filtration rate is poorly understood. Undoubtedly, reductions in the glomerular filtration rate may result in sodium retention, although in the presence of chronic renal disease or hypertension reduction of the glomerular filtration rate is often associated with a sodium diuresis. In patients with cirrhosis and ascites renal blood flow and the glomerular filtration rate are often normal or slightly reduced (Papper, Belsky, and Bleifer, 1959; Gornel, Lancestremere, Papper, and Lowenstein, 1962). However, where ascites is tense, inincreased abdominal pressure acting on the renal veins may reduce renal blood flow (Bradley and Bradley, 1947).

In terminal liver disease marked reduction of the glomerular filtration rate and renal blood flow may produce a syndrome of uraemia and renal failure with avid sodium retention (Shaldon and Walker, 1962). Measurement of renal blood flow by the para-amino-hippuric acid clearance technique is invalid under the circumstances as the extraction of para-amino-hippuric acid by the kidney is very poor, and so doubts are cast on the excessively low renal blood flow figures previously reported using this method (Papper et al., 1959; Lancestremere, Davidson, Earley, O'Brien, and Papper, 1962). However, studies with a nitrous oxide technique measuring renal blood flow suggest that there is indeed a marked reduction in oliguric patients with cirrhosis of the liver (Tyler, Jeffries, and Wilder, 1962) and, more recently, these results have been confirmed using a method of measuring renal blood flow which is independent of renal function (Shaldon, Higgs, Chiandussi, Walker, Garsenstein, and Ryder, 1962). The relationship between diuretic therapy and the reduction in renal blood flow and the glomerular filtration rate will be considered later. 


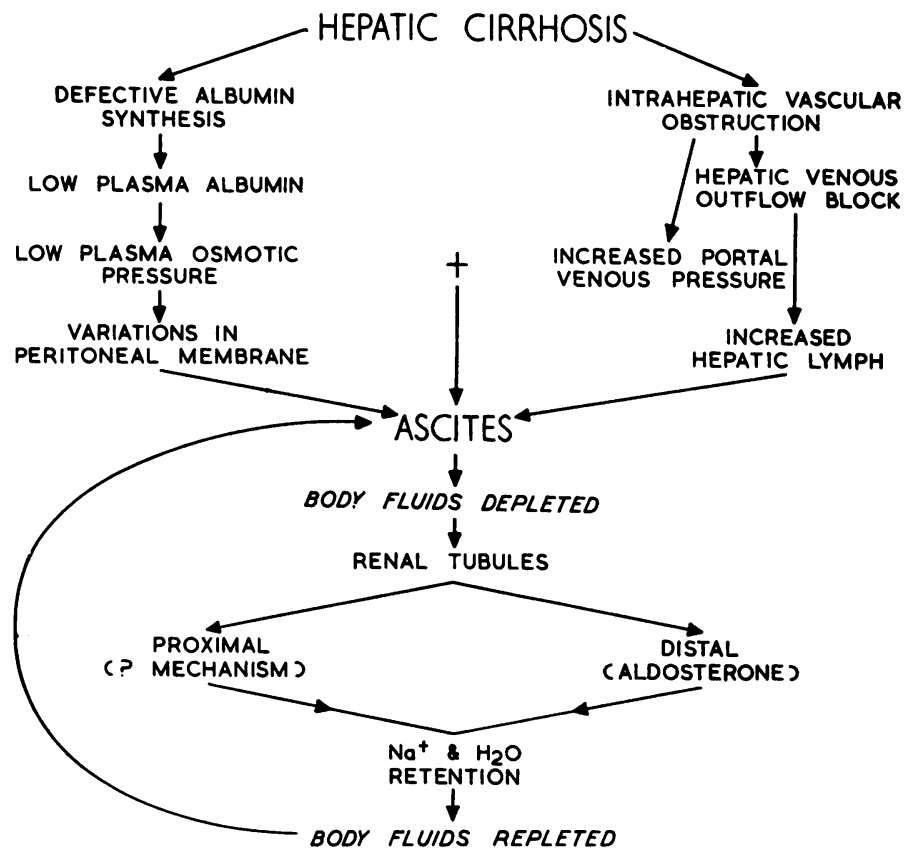

FIG. 2. Schematic summary of the pathogenesis of ascites.

\section{AETIOLOGICAL CONCLUSIONS}

The two most important factors in the development of ascites are failure of the liver to synthesize albumin, resulting in a low plasma osmotic pressure and portal venous hypertension. More fluid enters the peritoneal cavity than leaves it and ascites develops, resulting in a depletion of the effective body fluids and causing the renal tubules to reabsorb sodium excessively. The distal tubular effect is mediated through aldosterone; the mechanism of the proximal tubular action remains uncertain. In some instances renal blood flow and the glomerular filtration rate may be reduced, adding to sodium retention. It is possible that the peritoneal capillary membrane plays an active role in controlling the passage of fluid. Ascites may be partly formed from the hepatic lymph and the thoracic duct may play a part in its removal. By these various compensations body fluids are again depleted, more ascites is formed, and the whole cycle starts again.

\section{TREATMENT}

DIETARY The mainstay of the successful control of ascites in cirrhosis of the liver is rigid dietary therapy. In the past three years we have seen 87 patients with cirrhosis and fluid retention. Before the patients' referral for treatment the ascites was said to be intractable or 'resistant', unresponsive to diuretic therapy, and requiring repeated abdominal para- centesis. In 42 patients, the only change in treatment was to add a rigid restriction of salt to the previous dietary régime, allowing only 10 to $22 \mathrm{mEq}$. $(0 \cdot 25$ $0.5 \mathrm{~g}$. sodium daily), and diuresis ensued. With such a rigid diet, ascites occasionally resolved without diuretic therapy. Others have commented on the need, in spite of the use of newer available diuretics, for rigid dietary sodium restriction to control ascites (Summerskill, Clowdus, and Rosevear, 1961; Chalmers and Morrison, 1961). In a severe case even combinations of diuretics in large doses cannot compensate for a high-sodium diet. Potassium supplements are given routinely not only to combat the potassium depletion which is invariably present in patients forming ascites but also to prevent sodium depletion following diuretic therapy, especially with the thiazide group (Read, Haslam, Laidlaw, and Sherlock, 1958) and even with the aldosterone antagonists (Ross, 1961). Potassium supplements also have a diuretic potentiating action in their own right (Taylor and Faloon, 1959). Potassium supplements are most easily administered as an effervescent tablet containing $6.5 \mathrm{mEq}$. of potassium (potassium bicarbonate $500 \mathrm{mg}$. and potassium acid tartrate $300 \mathrm{mg}$.); each tablet is equivalent to $0.5 \mathrm{~g}$. potassium chloride (Hadgraft, 1960). Four tablets, dissolved in as little as $30 \mathrm{ml}$. of water, are taken four times daily, giving $104 \mathrm{mEq}$. potassium. This is the minimum routine daily dose. If azotaemia is present this quantity should be reduced or else serious hyperkalaemia may be produced. Gastrointestinal 
disturbances are very rare. Chandler, Hetherington, Stephenson, and Atkinson (1961) reported difficulty with this preparation due to potassium sticking to the glass after adding water; this has not been our experience with tablets prepared according to the original specification (Hadgraft, 1960).

Fluid intake is not usually restricted during the treatment of ascites. Retention of water is, however, sometimes important in the development of hyponatraemia in these patients. When this occurs, although an excess of both sodium and water is present in the body, retention of water is relatively greater than that of salt (Clowdus, Summerskill, Casey, Higgins, and Orvis, 1961). If cerebral symptoms suggestive of water intoxication are associated with a severe hyponatraemia, then it may be wise to restrict water, but if the hyponatraemia is asymptomatic this is not necessary. The demonstrable excess of total body sodium in the presence of hyponatraemia and the presence of a reduced total body potassium in the presence of hyperkalaemia clearly indicate the small value which may be placed on serum concentrations as indicative of changes in the total body content of electrolytes. There is no place for salt replacement therapy in the treatment of hyponatraemia associated with ascites and cirrhosis (Hecker and Sherlock, 1956). The administration of intravenous sodium to such a patient merely results in an increase in the ascitic fluid and, in the severely ill, in pulmonary oedema and death.

A good protein intake plays an important part in the rehabilitation process following the effective control of ascites. If the patient will tolerate an $80 \mathrm{~g}$. protein diet this is desirable. The danger of precipitating hepatic coma in patients on a highprotein diet must be realized (Sherlock, Summerskill, White, and Phear, 1954), and they will respond just as adequately to diuretic therapy on low-protein diets, although the rate of tissue protein accretion is slowed down. In certain instances, $\mathbf{4} \mathrm{g}$. neomycin daily by mouth will allow a higher protein intake without precipitating hepatic coma (Sherlock, Summerskill, and Dawson, 1956).

DIURETIC AGENTS In the past few years, two potent groups of diuretic agents, the thiazides and the aldosterone antagonists, have been added to the longused mercurial group. The different modes of action of each group and their additive effects have virtually eliminated the problem of refractory ascites (Fig. 3). However, complications of vigorous diuretic therapy may be serious and the need for long-term treatment in previously refractory cases has only recently been appreciated. Careful management and close supervision of such patients is necessary if the palliative value of the diuretic control of ascites is to be con-

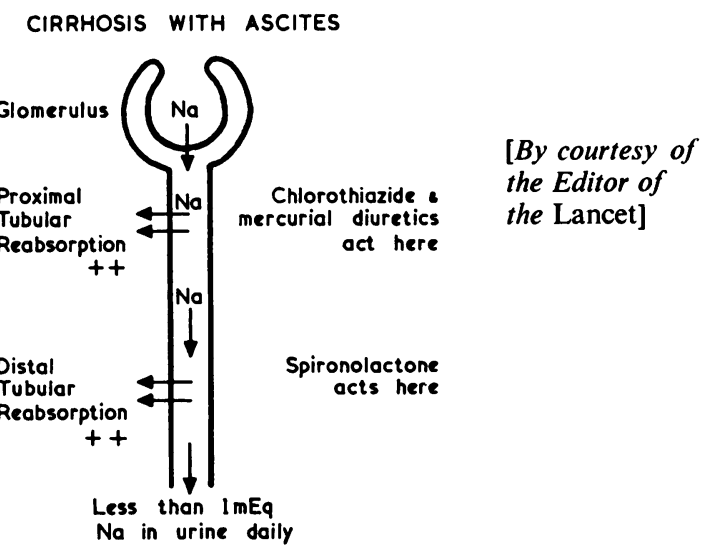

FIG. 3. Renal tubular site of action of diuretics: chlorothiazide and mercurial diuretics inhibit proximal sodium reabsorption whereas spironolactone acts by inhibiting the action of aldosterone on the distal tubule.

verted into a significant improvement in prognosis for the patient with 'resistant ascites'.

Chlorothiazide is the drug of choice for initial use, provided adequate potassium supplements are given. The main complication of this diuretic is potassium depletion and the newer thiazide diuretics have this same effect (Kerr, Read, and Sherlock, 1959). Chlorothiazide also causes an elevation of the serum uric acid level (Monroe, Grant, Sasahara, and Littman, 1959) and this has been confirmed in our cirrhotic patients on long-term thiazide therapy, although there have been no overt attacks of gout in any patient. In patients with hypertension, however, acute gouty arthritis has been precipitated by thiazide treatment (Aronoff and Barkum, 1961). Disturbances of carbohydrate metabolism with the exacerbation of diabetes and the production of hyperglycaemia has been reported in patients receiving thiazide for hypertension (Shapiro, Benedek, and Small, 1961) associated with possible pancreatic damage (Shanklin, 1962), and we have observed a patient developing acute pancreatitis while on longterm thiazide treatment. Agranulocytosis in association with thiazide therapy has been reported (Chrein and Rubin, 1962), probably due to the sulphonamide chemical structure of thiazide diuretics. Chlorothiazide also exhibits some carbonic anhydrase inhibitor activity resulting in an increase in the concentration of ammonia in the renal vein and a reduction in urinary ammonia excretion (Owen, Flanagan, and Tyor, 1959). The resultant rise in the blood ammonia level is clearly undesirable in patients with cirrhosis. Later thiazide analogues have less carbonic anhydrase inhibitor activity (Beyer and Baer, 1961). One such analogue, Quinethazone ${ }^{1}$, ${ }^{1}$ Lederle Laboratories Ltd 
seems to have an equivalent diuretic potency to chlorothiazide without the undesirable shift of ammonia from the urine to the renal vein (Shaldon, Walker, Ryder, Lawson, and Silva, 1963).

Chlorothiazide should be given every day in a dose of $2 \mathrm{~g}$. until the ascites is controlled. A more effective diuresis may be obtained if it is given at six-hourly intervals (Murphy, Casey, and Lasagna, 1961). After control of the ascites, chlorothiazide is given on alternate days three times a week with potassium supplements every day.

Mercurial diuretics, such as mersalyl, are not so potent as the thiazides but cause less potassium excretion and have no carbonic anhydrase inhibitor activity. In patients with signs of hepatic precoma who require diuretic therapy it is safer to start treatment with mersalyl, $2 \mathrm{ml}$. intramuscularly two or three times a week, rather than risk worsening the mental state with chlorothiazide.

Two-thirds of patients with cirrhosis and ascites respond to chlorothiazide alone (Shaldon, 1961). Additional diuretic therapy is needed in the remaining third.

The introduction of efficient, non-toxic, aldosterone antagonists has been a major advance in the diuretic therapy of ascites with cirrhosis of the liver. Spironolactone has been in use for three years and has been clearly shown to produce a sodium diuresis when used in combination with the thiazide or mercurial diuretics (Clowdus, Higgins, Rosevear, and Summerskill, 1960; Edmonds, 1960; Morrison and Chalmers, 1960; Shaldon et al., 1960; Lockwood, 1961 ; Ogden, Scherr, Spritz, and Rubin, 1961 ; Stewart and Constable, 1961). The rationale for the use of this combination depends on blocking two mechanisms for sodium reabsorption both of which are hyperactive in patients with resistant ascites (Fig. 4). Chlorothiazide and mercurial diuretics act at a proximal site in the renal tubule to inhibit sodium reabsorption. However, in the presence of excessive aldosterone secretion, sodium blocked from reabsorption at the proximal tubule is reabsorbed in exchange for potassium at a distal tubular site resulting in excessive potassium loss in the urine (Edmonds and Wilson, 1960) and hence no sodium diuresis ensues. Likewise, aldosterone antagonists are rarely effective when given alone as most of the sodium is reabsorbed proximal to their site of action (Shaldon et al., 1960). The combination of proximal and distal tubular diuretics, however, results in a synergistic action and a significant sodium diuresis. Potassium loss is reduced, although supplements of about 50 to $100 \mathrm{mEq}$. of potassium daily are required (Ross, 1961; Shaldon, 1961).

The problem of dosage and absorption of spironolactone has recently been investigated (Shaldon,

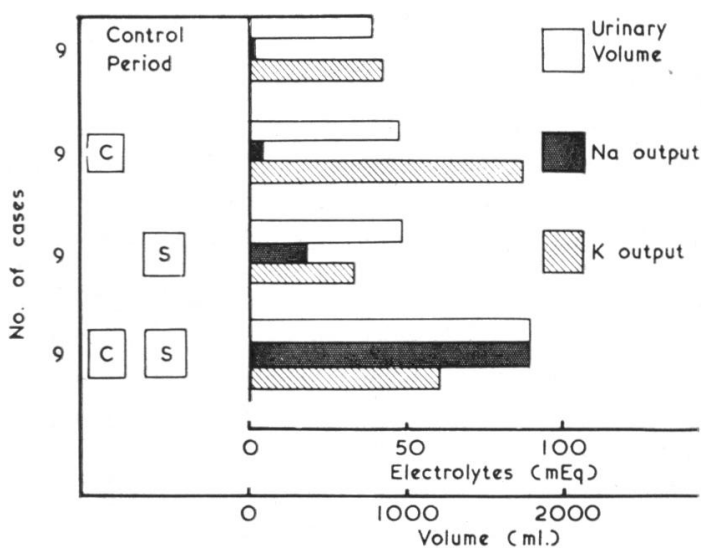

FIG. 4. Mean 24-hour urinary volume, sodium, and potassium output in patients with cirrhosis and resistant ascites during treatment with spironolactone $(S), 400 \mathrm{mg}$. daily for three days, and chlorothiazide $(C), 2 \mathrm{~g}$. daily for three days, alone and in combination. The means for each patient were derived from a five-day collection starting with each three-day course. [By courtesy of the Honorary Editors of the Proceedings of the Royal Society of Medicine.]

Ryder, and Garsenstein, 1963). Comparative studies were made on six patients with cirrhosis and controlled ascites, all of whom without diuretics excreted less than $1 \mathrm{mEq}$. sodium in the urine. Spironolactone requirements were first established, two patients requiring $400 \mathrm{mg}$., two $800 \mathrm{mg}$., and four $1,200 \mathrm{mg}$. daily in addition to chlorothiazide, $2 \mathrm{~g}$. daily. When a specially prepared microcrystalline tablet of spironolactone was substituted for the regular spironolactone an equal diuretic response was obtained with only a quarter of the dose. Furthermore, blood levels and urinary excretion of spironolactone were not significantly different with the two preparations. The older commercial tablet seems to have been poorly absorbed and the large doses required in some patients may have been due to this difficulty. However, patients who previously required high doses of spironolactone still need one quarter of the dose of the new microcrystalline spironolactone (Aldactone A). The introduction of the new microcrystalline preparation has reduced the cost of spironolactone by two-thirds. Initial treatment with spironolactone (Aldactone A) should consist of $100 \mathrm{mg}$. daily. However, one-third of patients with cirrhosis and ascites requiring this drug will not respond at this dose level and as much as $300 \mathrm{mg}$. daily may be necessary. We have never seen a diuresis induced with a dose higher than $300 \mathrm{mg}$. of Aldactone A (1,200 mg. of the old preparation). The initial response to spironolactone is slow and there is a delay of 24 to 48 hours before the drug acts. Chlorothiazide should be omitted on the first day 
to avoid increasing potassium loss. Treatment should then be continuous with both drugs. When ascites is well controlled, and depending on the severity of the fluid retention, it may be reduced to three to five days weekly. Occasionally, a patient is so resistant that daily therapy is required even after full control of fluid retention.

Sixteen patients requiring combined diuretic therapy with spironolactone and chlorothiazide left hospital with the ascites controlled and all were followed up for three years. Eight patients died of hepatic failure in the first year. The other eight patients are all well, having regained their body weight before ascites developed, and are back at useful work (Fig. 5). Three of these patients have required 800 to $1,200 \mathrm{mg}$. daily of old spironolactone ( 200 to $300 \mathrm{mg}$. of Aldactone A) for three years to maintain themselves free of ascites although they have received chlorothiazide, $2 \mathrm{~g}$. daily with potassium supplements, and also remained on a lowsodium diet. Two patients have been able, after one year, to relax their dietary salt restriction. Three patients, after two years' diuretic therapy, do not require drugs or dietary salt restriction. Similar results have recently been reported by Summerskill et al. (1961) in a follow-up of 13 patients with 'resistant' ascites.

Occasionally, the diuretic response to even large doses of spironolactone with chlorothiazide is inadequate and further therapy is required. Metopirone, an $11 \beta$ hydroxylase inhibitor of the synthesis of aldosterone, has been used to treat ascites (Holub and Jailer, 1960). It has also been used to potentiate the sodium diuresis of spironolactone and chlorothiazide in two patients with cirrhosis and resistant ascites (Shaldon and McLaren, 1960). Subsequently, three other patients have been treated and in every instance a diuresis was initiated after other measures had failed. In addition, one patient who had failed to react to spironolactone, $1,200 \mathrm{mg}$. (old preparation), with chlorothiazide, $2 \mathrm{~g}$. daily, and prednisolone, $20 \mathrm{mg}$. daily, mersalyl, $2 \mathrm{ml}$. intramuscularly on alternate days, and Mannitol, 2 litres $10 \%$ on alternate days, had a diuresis when metopirone, $2,700 \mathrm{mg}$. daily, was added to this armamentarium. This patient required spironolactone, metopirone, and chlorothiazide for 18 months, any attempt to withdraw either aldosterone antagonist resulting in reaccumulation of ascitic fluid.

More recently, a new diuretic, a pteridine derivative (Triamterene, SKF.8542) has become available for study (Laragh, Reilly, Stites, and Angers, 1961 ; Herken and Senft, 1961; Donnelly, Turner, and Sowry, 1962). This drug produces a sodium diuresis with potassium retention in the normal subject on a normal diet who is not excreting excess aldosterone and in adrenalectomized patients not on a saltretaining steroid (Liddle, 1961). It is not therefore a true aldosterone antagonist. Nevertheless, it is capable of increasing urinary sodium output in cirrhotic patients with ascites and will also further potentiate the combination of chlorothiazide and spironolactone (Shaldon and Ryder, 1962). The main complication to its use is a very occasional tendency to azotaemia if therapy is too intensive and the glomeiular filtration rate falls dramatically. This complication is, however, completely reversible when therapy is given intermittently. We have now treated three patients with this drug for over 12 months as out-patients.

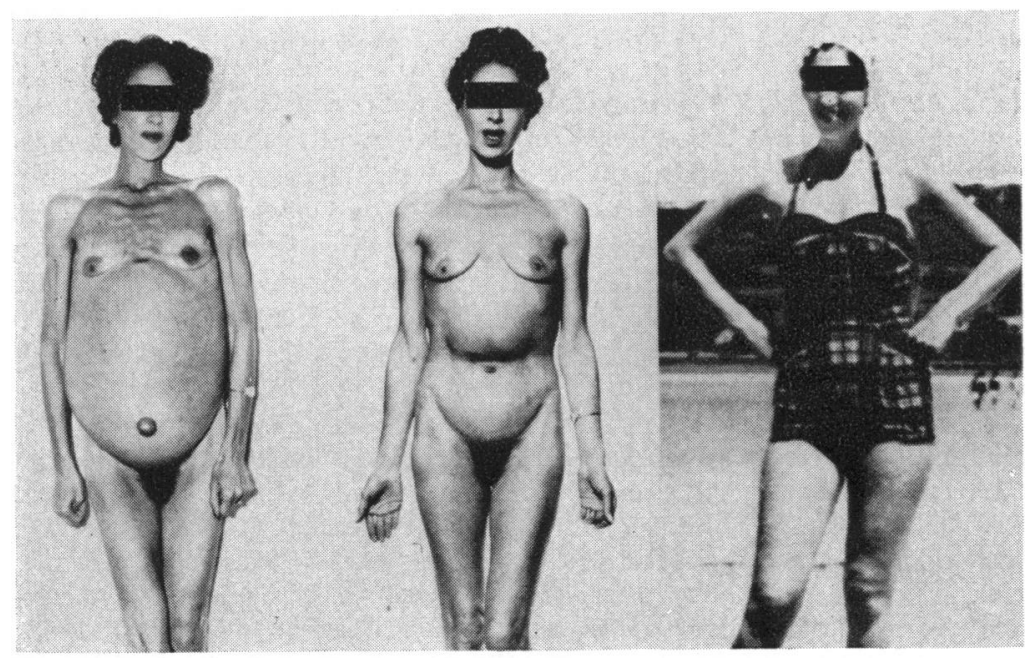

a b
FIG. 5. Long-term combined diuretic therapy in cirrhosis:

(a) Resistant ascites in a 32-year-old woman with nonalcoholic cirrhosis.

(b) After three months in hospital on combined diuretic therapy and salt restriction.

(c) After three years' treatment with spironolactone, chlorothiazide, and salt restriction. The patient is now leading an active life, having returned to her pre-ascitic body weight and stature. [By courtesy of the Editor of Rev. Int. Hepatol.] 
Relative water over sodium retention of ten develops during intensive diuretic therapy in cirrhotic patients with ascites, especially when free water clearance is reduced by chlorothiazide and spironolactone therapy. The resultant hyponatraemia may be asymptomatic, may result in listlessness, or may lead to hepatic precoma. In these circumstances water diuretics are required. Mannitol acts as an osmotic diuretic and so increases the 'free water clearance' in such patients; the serum sodium level then rises (Shaldon, 1960). Two litres 10\% Mannitol are given intravenously and may need to be repeated as often as on alternate days to achieve an effect. Rigors associated with pyrogen reactions are a complication of this therapy but may be effectively controlled with antipyretics such as aspirin. Prednisone gives the same result by increasing the glomerular filtration rate and reducing tubular reabsorption of water (Chalmers and Morrison, 1961). Unfortunately, fulminant infections often complicate the longcontinued use of steroids in these patients (Stormont, Crabbe, Fast, Wolfe, and Davidson, 1959). Both Mannitol and prednisone will potentiate a sodium diuresis induced by chlorothiazide and spironolactone. Prednisone has also been used as a sodium diuretic in its own right (Cattan and Vesin, 1957). Other agents used to potentiate a diuresis include calcium gluconate (Dingman and Yoffee, 1960) and acidifying amino-acids (arginine and lysine) (Gidekel, Sherlock, Peterson, and Vanamee, 1960; Lasser, Schoenfeld, and Friedberg, 1960), which probably act as osmotic diuretics, although this is not certain.

The main danger of combined diuretic therapy is the development of electrolyte imbalance due to disproportionate loss of sodium and potassium with relative water retention. If the patient becomes precomatose therapy must be stopped. However, in the absence of symptoms, hyponatraemia does not require treatment and in particular sodium therapy must never be given. Azotaemia and progressive renal failure are occasionally precipitated by overintensive diuretic therapy and under these circumstances a reduction in renal blood flow is probably the operative factor. This complication is rarely seen in the absence of terminal liver failure and occurs as frequently in patients who are not on diuretics as in those to whom diuretic therapy is given (Hecker and Sherlock, 1956; Vesin, 1962). The high incidence of renal failure associated with diuretic therapy which had previously been reported (Cattan, Caroli, Debray, Pequignot, and Vesin, 1962) probably reflects results in a severely ill group of cirrhotic patients who were alcoholics. Nevertheless, in such patients stopping all diuretics and performing a small paracentesis may be the best management. Reduction in the intra-abdominal pressure may relieve tension on the renal veins and so increase renal blood flow (Bradley and Bradley, 1947). The use of haemodialysis to treat the renal failure and ascites in such patients has been disappointing (Shaldon and Walker, 1962), for in them the problem is not only fluid retention but failure of all the liver's functions. Control of one facet cannot be expected to reverse other abnormalities such as haemorrhage or deepening jaundice.

Although sufficient diuretic agents acting at different tubular sites are available, the ideal diuretic has not yet arrived. Resistant ascites is no longer a problem, but electrolyte disturbances do result from combined diuretic therapy and the prevention of these and their management remain difficult.

OTHER MEASURES Haemodialysis has been used to remove ascitic fluid by a process of ultrafiltration, so removing plasma water (Goldsmith, Nakamoto, and Kolff, 1960). We have dialysed one patient with cirrhosis and ascites with severe hyponatraemia. After a haemodialysis lasting six hours with removal of water by ultrafiltration the serum sodium level rose from 98 to $120 \mathrm{mEq}$. per litre with removal of 6 litres of ascitic fluid. There was a commensurate improvement in the patient's condition.

The management of ascites with intensive, combined diuretic and dietary therapy has for practical purposes eliminated other methods which have been proposed. These include salt-free human albumin infusions which are said to be effective in promoting a diuresis in diuretic-resistant patients (Dykes, 1961; Losowsky and Atkinson, 1961). Resistance, however, was based on the failure of only one diuretic without the addition of spironolactone. In a subsequent controlled trial, salt-free human albumin infusions, given over many months, have been shown to have no effect on life expectancy, well-being, working capacity, control of fluid retention, or drug requirements of patients with resistant ascites, provided that aldosterone antagonists, chlorothiazide, and a strict low-sodium diet were also contained in the therapeutic régime (Wilkinson and Sherlock, 1962). An alternative to salt-free human albumin has been the removal of sodium from ascitic fluid after paracentesis by dialysis with an artificial kidney. The salt-free ascitic fluid is then given back to the patient intravenously (Britton, 1961).

Abdominal paracentesis historically antedates most other therapeutic measures in the treatment of ascites. The hazards of paracentesis in the cirrhotic patient include electrolyte disturbances, uraemia, infection, haemorrhage, protein depletion, and hepatic coma (Nelson, Rosenbaum, and Strauss, 1951; Liebowitz, 1962; Sherlock, 1963). In spite of these dangers many patients still receive unnecessary and 
potentially dangerous peritoneal taps. Paracentesis is justified only to relieve tense ascites at the outset of diuretic therapy and for diagnostic purposes to exclude a complicating hepatoma or peritoneal infection. Tuberculous peritoneal disease is not an uncommon, unsuspected complication of alcoholic cirrhosis (Burack and Hollister, 1960).

Peritoneal caval shunt is an alternative surgical measure designed to drain ascitic fluid internally (Smith, 1962). A catheter with a one-way SpitzHolter valve drains fluid from the peritoneal cavity into the inferior vena cava via the femoral vein. Previously intractable ascites was controlled in one patient, although diuretic therapy was still necessary (Smith, Preshaw, and Bisset, 1962). Other drainage methods include absorption of ascitic fluid by an everted loop of intestine (ileoentectropy) (Christeas, Kottakis, and Georgiades, 1961) and drainage of ascitic fluid into the pleural cavity (El-Toraei, 1961).

Dumont and Mulholland (1960) observed an increased flow of thoracic duct lymph in cirrhotic patients with ascites. Drainage of the lymph by cannulating the thoracic duct resulted in rapid removal of ascites.

Portacaval anastomosis is the most valuable surgical treatment of ascites. Effective decompression of the portal bed, with lowering of the portal pressure, often results in permanent relief of ascites and restoration of normal salt tolerance. The choice of portacaval anastomoses lies between end-to-side (Blakemore, 1952; Eisenmenger and Nickel, 1956; Ekman, 1957; Crane, 1962; Gliedman, Sellers, Burkle, and Enquist, 1962), side-to-side (Welch et al., 1959; Barker and Reemtsma, 1960), or double sideto-side (McDermott, 1960), both ends of the portal vein being implanted separately into the inferior vena cava. The theoretical haemodynamic advantages associated with side-to-side portacaval anastomosis, including relief of the hepatic outflow block, have not been substantiated in practice (Crane, 1962).

Although portacaval anastomosis will cure ascites in cirrhotic patients retaining fluid but otherwise in good general condition, this operation carries a $50 \%$ mortality (Blakemore, 1952). There is a high incidence of portal systemic encephalopathy (episodic hepatic stupor) afterwards (Read, Laidlaw, and Sherlock, 1961). Furthermore, ascites is rarely due to portal hypertension alone and implies defective hepatocellular function. Hypoalbuminaemia persists post-operatively and ankle oedema often develops. The operation should be reserved for those whose financial position or remoteness from medical supervision puts them in a position where they cannot receive a low-sodium diet and adequate long-term diuretic therapy.

\section{REFERENCES}

Aronoff, A., and Barkum, H. (1961). Hyperuricemia and acute gouty arthritis precipitated by thiazide derivatives. Canad. med. Ass. J., 84, 1181-1186.

Baggenstoss, A. H., and Cain, J. C. (1957). The hepatic hilar lymphatics of man. New Engl. J. Med., 256, 531-535.

Barker, H. G., and Reemtsma, K. (1960). The portacaval shunt operation in patients with cirrhosis and ascites. Surgery, 48, 142-154.

Berman, J. K., and Hull, J. E. (1952). Experimental ascites-its production and control. lbid., 32, 67-75.

Bernstein, S. H., Weston, R. E., Ross, G., Grossman, J., Hanenson, I. B., and Leiter, L. (1953). Studies on intravenous water diuresis and nicotine and pitressin antidiuresis in normal subjects and patients with liver disease. J. clin. Invest., 32, 422-427.

Beyer, K. H., and Baer, J. E. (1961). Physiological basis for the action of newer diuretic agents. Pharmacol. Rev., 13, 517-562.

Birchard, W. H., Prout, T. E., Williams, T. F., and Rosenbaum, J. D. (1956). Diuretic responses to oral and intravenous water loads in patients with hepatic cirrhosis. J. Lab. clin. Med., 48, 26-35.

Birkenfeld, L. W., Leibman, J., O'Meara, M. P., and Edelman, I. S. (1958). Total exchangeable sodium, total exchangeable potassium, and total body water in edematous patients with cirrhosis of the liver and congestive heart failure. J. clin. Invest., 37, 687-698.

Bjørneboe, M., Brun, G., and Raaschou, F. (1949). Colloid osmotic pressure in chronic hepatitis. Arch. intern. Med., 83, 539-546.

Blakemore, A. H. (1952). Portacaval shunting for portal hypertension. Surg. Gynec. Obstet., 94, 443-454.

Bolton, C. (1914). The pathological changes in the liver resulting from passive venous congestion experimentally produced. J. Path. Bact., 19, 258-264.

Bongiovanni, A. M., and Eisenmenger, W. J. (1951). Adrenal cortical metabolism in chronic liver disease. J. clin. Endocr., 11, 152-172.

Bradley, S. E., and Bradley, G. P. (1947). The effect of increased intra-abdominal pressure on renal function in man. $J$. clin. Invest., 26, 1010-1022.

Britton, R. C. (1961). A new technique for rapid control of cirrhotic ascites. Arch. Surg., 83, 364-369.

Burack, W. R., and Hollister, R. M. (1960). Tuberculous peritonitis. A study of forty-seven proved cases encountered by a General Medical Unit in twenty-five years. Amer. J. Med., 28, 510-523.

Cain, J. C., Grindley, J. H., Bollman, J. L., Flock, E. V., and Mann, F. C. (1947). Lymph from liver and thoracic duct. An experimental study. Surg. Gynec, Obstet., 85, 559-562.

Cattan, R., Caroli, J., Debray, C., Pequignot, G., and Vesin, P. (1962). Possibilités et limites de la médication diurétique dans les cirrhoses du foie avec ascite etoedèmes. Presse méd., 70, 337-338.

Cattan, R., and Vesin, P. (1957). Etat actuel du traitement des cirrhoses ascitiques par la delta-cortisone. Sem. Hôp, Paris, 33, 76-79.

Chalmers, T. C., and Morrison, R. S. (1961). Diuretic and steroid therapy in liver disease. In Progress in Liver Diseases, vol. 1, pp. 338-350. Edited by H. Popper, and F. Schaffner, Grune and Stratton, New York.

Chandler, N., Hetherington, C., Stephenson, A. N., and Atkinson, M. (1961). Potassium replacement therapy. Gut, 2, 186-187.

Cherrick, G. R., Kerr, D. N. S., Read, A. E., and Sherlock, S. (1960). Colloid osmotic pressure and hydrostatic pressure relationships in the formation of ascites in hepatic cirrhosis. Clin. Sci., 19, 361-375.

Chrein, M. B., and Rubin, I. L. (1962). Agranulocytosis secondary to hydrochlorothiazide therapy, J. Amer. med. Ass., 181, 54-55.

Christeas, N., Kottakis, G., and Georgiades, N. (1961). Absorption of ascitic fluid by intestinal entectropy. An experimental study. J. int. Coll. Surg., 35, 446-450.

Clowdus, B. F., II, Higgins, J. A., Rosevear, J. W., and Summerskill, W. H. J. (1960). Treatment of 'refractory' ascites with a new aldosterone antagonist in patients with cirrhosis. Proc. Mayo Clin., 35, 97-105.

—, Summerskill, W. H. J., Casey, T. H., Higgins, J. A., and Orvis, A. L. (1961). Isotope studies of the development of water and electrolyte disorders and azotemia during the treatment of ascites. Gastroenterology, 41, 360-370. 
Crane, C. (1962). The choice of shunt procedure for cirrhotic patients with variceal bleeding, ascites, and hypersplenism. Surg. Gynec. Obstet., 115, 12-28.

De Deuxchaisnes, C. N., Collet, R. A., Busset, R., and Mach, R. S. (1961). Exchangeable potassium in wasting, amyotrophy, heart-disease, and cirrhosis of the liver. Lancet, 1, 681-687.

Dingman, J. F., and Yoffee, H. F. (1960). Effect of calcium gluconate and adrenal steroids on sodium and water excretion in patients with cirrhosis and ascites. New Engl. J. Med., 262, 585-590.

Donnelly, R. J., Turner, P., and Sowry, G. S. C. (1962). Clinical trial of new oral diuretic-SKF 8542. Lancet, 1, 245-247.

Dumont, A. E., and Mulholland, J. H. (1960). Flow rate and composition of thoracic-duct lymph in patients with cirrhosis. New Engl. J. Med., 263, 471-474.

Dykes, P. W. (1961). A study of the effects of albumin infusions in patients with cirrhosis of the liver. Ouart. J. Med., 30, 297-327.

Edmonds, C. J. (1960). An aldosterone antagonist and diuretics in the treatment of chronic oedema and ascites. Lancet, 1, 509-515.

, and Wilson, G. M. (1960). The action of hydroflumethiazide in relation to adrenal steroids and potassium loss. Ibid., 1, 505-509.

Eisenmenger, W. J. (1952). Role of sodium in the formation and control of ascites in patients with cirrhosis. Ann. intern. Med., 37, 261-272.

- and Nickel, W. F. (1956). Relationship of portal hypertension to ascites in Laennec's cirrhosis. Amer. J. Med., 20, 879-889.

Ekman, C. A. (1957). Portal hypertension. Acta. chir. scand., suppl. 222.

El-Toraei, I. (1961). Surgical treatment of cirrhotic ascites with a new operation (Pleuroperitoneostomy). J. int. Coll. Surg., 35, 436-445.

Faloon, W. W., Eckhardt, R. D., Murphy, T. L., Cooper, A. M., and Davidson, C. S. (1949). An evaluation of the human serum albumin in the treatment of cirrhosis of the liver. J. clin. Invest., 28, 583-594.

Gidekel, L. I., Sherlock, P., Peterson, A. S., and Vanamee, P. (1960). Management of refractory fluid retention with a combination of L-arginine monohydrochloride and mercurials. New Engl. J. Med., 263, 221-226.

Giges, B., and Kunkel, H. G. (1954). Osmotic pressure measurements of serum and ascitic fluid in patients with cirrhosis of the liver. J. clin. Invest., 33, 257-263.

Gliedman, M. L., Sellers, R. D., Burkle, J. S., and Enquist, I. F. (1962). Cirrhosis with ascites: hemodynamic observations. Ann. Surg., 155, 147-152.

Goldsmith, H. J., Nakamoto, S., and Kolff, W. J. (1960). Expanding the indications for treatment with the artificial kidney. Lancet, 2, 111-114.

Gornel, D. L., Lancestremere, R. G., Papper, S., and Lowenstein, L. M. (1962). Acute changes in renal excretion of water and solute in patients with Laennec's cirrhosis, induced by the administration of the pressor amine metaraminol. J. clin. Invest., 41, 594-603.

Hadgraft, J. W. (1960). Preparations for water and electrolyte balance. Pharm. J., 184, 277-279.

Hecker, R., and Sherlock, S. (1956). Electrolyte and circulatory changes in terminal liver failure. Lancet, 2, 1121-1125.

Herken, H., and Senft, G. (1961). 2-, 4-, 7-Triamino-6-phenylpteridinals 'Aldosteronantagonist'. Klin. Wschr., 39, 1205-1206.

Higgins, G., Kelsall, A. R., O'Brien, J. R. P., Stewart, A. M., and Witts, L. J. (1947). Ascites in chronic disease of the liver. Quart. J. Med., 16, 263-274.

Holub, D. A., and Jailer, J. W. (1960). Sodium and water diuresis in cirrhotic patients with intractable ascites following chemical inhibition of aldosterone synthesis. Ann. intern. Med., 53, 425-444.

Hyatt, R. E., and Smith, J. R. (1954). The mechanism of ascites: a physiologic appraisal. Amer. J. Med., 16, 434-448.

Kerr, D. N. S., Read, A. E., and Sherlock, S. (1959). Dihydrochlorothiazide in control of ascites. Lancet, 1, 1221-1223.

Lancestremere, R. G., Davidson, P. L., Earley, L. E., O'Brien, F. J., and Papper, S. (1962). Simultaneous determination of cardiac output and renal hemodynamics in decompensated Laennec's cirrhosis. Clin. Res., 10, 67.

Laragh, J. H., Reilly, E. B., Stites, T. B., and Angers, M. (1961). Pteridine compound as an inhibitor of aldosterone action in man. Fed. Proc., 20, 410.

Lasser, R. P., Schoenfeld, M. R., and Friedberg, C. K. (1960) L-Lysine Monohydrochloride. A clinical study of its action as a chlorurectic acidifying adjuvant to Mercurial Diuretics. New Engl. J. Med., 263, 728-733.

Lee, J., and Bisset, G. W. (1958). The secretion of neurohypophyseal hormones in man with special reference to liver disease. Proc. roy. Soc. Med., 51, 361-362.

Leger, L., and Guyet, P. (1957). La stase lymphatique dans les cirrhoses du foie. Presse méd., 65, 1930-1932.

Liddle, G. W. (1961). Specific and non-specific inhibition of mineralocorticoid activity. Metabolism, 10, 1021-1030.

Liebowitz, H. R. (1962). Hazards of abdominal paracentesis in the cirrhotic patient. N.Y.S. J. Med., 62, 1822-1826.

Lockwood, C. H. (1961). Spironolactone (Aldactone) therapy for ascites due to cirrhosis of the liver. Canad. med. Ass. J., 85, 631-637.

Losowsky, M. S., and Atkinson, M. (1961). Intravenous albumin in the treatment of diuretic-resistant ascites in portal cirrhosis. Lancet, 2, 386-389.

McDermott, W. V. Jr. (1958). The treatment of cirrhotic ascites by combined hepatic and portal decompression. New Engl. J. Med., 259, 897-901.

-, (1960). The double portacaval shunt in the treatment of cirrhotic ascites. Surg. Gynec. Obstet., 110, 457-469.

Mills, I. H., de Wardener, H. E., Hayter, C. J., and Clapham, W.F. (1961). Studies on the afferent mechanism of the sodium chloride diuresis which follows intravenous saline in the dog. Clin. Sci., 21, 259-264.

Monroe, K. E., Grant, L. H., Sasahara, A. A., and Littmann, D. (1959). Effect of chlorothiazide therapy on serum uric acid and uric acid excretion. New Engl. J. Med., 261, 290-292.

Morrison, R. S., and Chalmers, T. C. (1960). Combined diuretic and steroid therapy in cirrhosis with ascites. Ann. N.Y. Acad. Sci., 88, 907-914.

Murphy, J., Casey, W., and Lasagna, L. (1961). The effect of dosage regimen on the diuretic efficacy of chlorothiazide in human subjects. J. Pharmacol. exp. Ther., 134, 286-290.

Nelson, W. P., III, Rosenbaum, J. D., and Strauss, M. B. (1951). Hyponatremia in hepatic cirrhosis following paracentesis. J. clin. Invest., 30, 738-744.

Ogden, D. A., Scherr, L., Spritz, N., and Rubin, A. L. (1961). A comparison of the properties of chlorothiazide, spironolactone and a combination of both as diuretic agents. New Engl. J. Med., 265, 358-362.

Owen, E. E., Flanagan, J. F., and Tyor, M. P. (1959). Kidney as a source of blood ammonia: effect of chlorothiazide. Proc. Soc. exp. Biol. (N.Y.), 102, 696-697.

Papper, S., Belsky, J. L., and Bleifer, K. H. (1959). Renal failure in Laennec's cirrhosis of the liver. 1. Description of clinical and laboratory features. Ann. intern. Med., 51, 759-773.

Post, J., and Patek, A. J. Jr. (1942). Serum proteins in cirrhosis of the liver. I. Relation to prognosis and to formation of ascites. Arch. intern. Med., 69, 67-82.

Read, A. E., Haslam, R. M., Laidlaw, J., and Sherlock, S. (1958) Chlorothiazide in control of ascites in hepatic cirrhosis. Brit. med. J., 1, 963-966.

_, Laidlaw, J., and Sherlock, S. (1961). Neuropsychiatric complications of portacaval anastomosis. Lancet, 1, 961-963.

Ross, E. J. (1961). Importance of potassium supplements during the use of spironolactone and thiazide diuretics. Brit. med. J., 1, 1508-1510.

Schedl, H. P., and Bartter, F. C. (1960). An explanation for and experimental correction of the abnormal water diuresis in cirrhosis. J. clin. Invest., 39, 248-261.

Schoenberger, J. A., Kroll, G., Sakamoto, A., and Kark, R. M. (1952). Investigation of the permeability factor in ascites and edema using albumin tagged with ${ }^{131}$. Gastroenterology, 22, 607-622.

Shaldon, S. (1960). The mechanism of salt and water retention in cirrhotic patients with refractory ascites. Excerpta Med. (Amst.), Int. Cong. Ser., 29, 74.

- (1961). The clinical application of aldosterone antagonists in the treatment of oedema. Proc. roy. Soc. Med., 54, 259-261.

(1962). Traitment de l'ascite chronique chez le cirrhotique. Rev. int. Hépat., 12, 1093-1105.

—, Dolle, W., Guevara, L., Iber, F. L., and Sherlock, S. (1961). Effect of Pitressin on the splanchnic circulation in man. Circulation, 24, 797-807.

- Higgs, B., Chiandussi, L., Walker, G., Garsenstein, M., and Ryder, J. (1962). Measurement of renal blood flow in man with the use of indocyanine green infused into the renal artery. J. Lab. clin. Med., 60, 954-966. 
Shaldon, and McLaren, J. R. (1960). An 11 -Hydroxylase inhibitor in the treatment of resistant ascites. Lancet, 2, 1330-1332.

- , and Ryder, J. A. (1962). Use of apteridine diuretic (Triamterene) in treatment of hepatic ascites. Brit. med. J., 2, 764-767.

-, Ryder, J. A., and Garsenstein, M. (1963). A comparison of the use of Aldactone and Aldactone $A$ in the treatment of hepatic ascites. Gut, 4, 16-19.

- and Sherlock, S. (1960). Resistant ascites treated by combined diuretic therapy (spironolactone, Mannitol and chlorothiazide). Ibid., 1, 609-613.

Acta hepato-splend. (Stuttg.), in press.

_- Walker, J. G., Ryder, J., Lawson, T.R. and Silva, H. (1963). A comparison of the effect of chlorothiazide and quinethazone on the renal handling of ammonia, electrolytes and water. In preparation.

Shanklin, D. R. (1962). Pancreatic atrophy apparently secondary to hydrochlorothiazide. New Engl. J. Med., 266, 1097-1099.

Shapiro, A. P., Benedek, T. G., and Small, J. L. (1961). Effect of thiazides on carbohydrate metabolism in patients with hypertension. Ibid., 265, 1028-1033.

Sherlock, S., Summerskill, W. H. J., White, L. P., and Phear, E. A. (1954). Portal-systemic encephalopathy: neurological complications of liver disease. Lancet, 2, 453-457.

, and Dawson, A. M. (1956). The treatment and prognosis of hepatic coma. Ibid., 2, 689-694.

- (1959). Mechanisms for the formation of ascites. In discussion on ascites and its management. Proc. roy. Soc. Med., 52, 247-249.

- (1963). Diseases of the Liver and Biliary System, 3rd ed. Blackwell, Oxford.

Smith, A. N. (1962). Peritoneocaval shunt with a Holter valve in the treatment of ascites. Lancet, 1, 671-672.

- Preshaw, R. M., and Bisset, W. H. (1962). The drainage of resistant ascites, by a modification of the Spitz-Holter valve technique. J. roy. Coll. Surg. Edinb., 7, 289-294.

Starling, E. H. (1896). On the absorption of fluids from the connective tissue spaces. J. Physiol. (Lond.), 19, 312-326.
Stewart, W. K., and Constable, L. W. (1961). The diuretic response to hygroton, mersalyl, and aldactone. Lancet, 1, 523-529.

Stormont, J. M., Crabbe, J., Fast, B., Wolfe, S. J., and Davidson, C. S. (1959). The effect of prednisone and amphenone on fluid and electrolyte balance and on aldosterone excretion of patients with cirrhosis and ascites. J. Lab. clin. Med., 53, 396-416.

Summerskill, W. H. J., Clowdus, B. F., II, and Rosevear, J. W. (1961). Long term medical management and complications of 'resistant' ascites. Gut, 2, 285-296.

Taylor, F. F., and Faloon, W. W. (1959). The role of potassium in the natriuretic response to a steroidal lactone (SC-9420). J. clin. Endocr., 19, 1683-1687.

Tyler, J. M., Jeffries, J. L., and Wilder, C. E. (1962). A study of the renal blood flow by nitrous oxide technique in normal and oliguric patients with cirrhosis of the liver. Clin. Res., 10, 194.

Ulick. S. (1959). In discussion on R. E. Peterson's paper, 'The miscible pool and turnover rate of adrenocortical steroids in man.' Recent Progr. Hormone Res.. 15, 270-271.

Vesin, P. (1962). Functional renal failure in the course of ascitic cirrhosis-Mechanisms, diagnosis and treatment. Acta hepatosplenol. (Stuttg.). in press.

Volwiler, W., Grindlay, J. H., and Bollman, J. L. (1950). The relation of portal vein pressure to the formation of ascites-an experimental study. Gastroenterology, 14, 40-55.

Wardener, de H. E., Mills, I. H., Clapham, W. F., and Hayter, C. J. (1961). Studies on the efferent mechanism of the sodium diuresis which follows the administration of intravenous saline in the dog. Clin. Sci., 21, 249-258.

Welch, C. S., Welch, H. F., and Carter, J. H. (1959). The treatment of ascites by side to side portacaval shunt. Ann. Surg., 150, 428-444.

Wilkinson, P., and Sherlock, S. (1962). The effect of repeated albumin infusions in patients with cirrhosis. Lancet, 2, 1125-1129.

normal subjects and patients with cirrhosis measured by 131 iodine labelled human albumin. Clin. Sci. In press. 